\title{
Evolutionary relationships of West Nile virus detected in mosquitoes from a migratory bird zone of Colombian Caribbean
}

Richard Hoyos López ${ }^{1,2^{*}}$, Sandra Uribe Soto ${ }^{2}$ and Juan Carlos Gallego-Gómez ${ }^{1 *}$

\begin{abstract}
Background: West Nile virus (WNV) is a member of the genus Flavivirus, and it is transmitted between Culex sp. mosquitoes and avian hosts. Equids and humans are commonly infected with WNV as dead-end hosts, and the signs and symptoms of infection range from mild illness to neurologic symptoms as encephalitis, meningitis and sometimes death. Previous phylogenetic studies have classified WNV into six genetically distinct lineages and provided valuable insight on WNV dispersal patterns within the Americas and its emergence in different geographic areas. In this study, we isolated, sequenced and genetically characterized the NS5 and envelope genes for two WNV strains detected from Northern of Colombia. Herein we describe the evolutionary relationships with representative WNV-strains isolated in a variety of epidemic outbreaks and countries, to define the phylogeographic origin and possible implications in the epidemiology of this emergent virus in Colombia.
\end{abstract}

Findings: Fragments of the NS5 and Envelope genes were amplified with RT-PCR and sequenced to obtain 1186-nt and 1504-nt portions, respectively. Our sequences were aligned with 46 sequences from WNV-strains collected in the U.S., Mexico and Argentina for phylogenetic reconstruction using Bayesian methods. Sequence analyses identified unique non-synonymous substitutions in the envelope gene of the WNV strains we detected, and our sequences clustered together with those from the attenuated Texas - 2002 genotype.

Conclusions: A new strain closely related to attenuated strains collected in Texas during 2002 was identified from Colombia by phylogenetic analysis. This finding may explain the absence of human/equine cases of WNV-encephalitis or severe disease in Colombia and possibly other regions of South America. Follow-up studies are needed in ecosystems used by migratory birds areas and virological/entomological surveillance.

\section{Findings Introduction}

West Nile virus (WNV) is a member of the Japanese encephalitis antigenic complex (JEV) within the Flavivirus genus and is transmitted by Culex spp. mosquitoes among birds. Other vertebrates such as mammals and reptiles also become infected [1]. Human infection with WNV causes mild to severe illness, sometimes affecting the nervous systems and provoking encephalitis, meningitis and death [2].

\footnotetext{
*Correspondence: rhoyoslopez@gmail.com; juanc.gallegogomez@gmail.com ${ }^{1}$ Molecular and Translational Medicine Group, Medical Research Institute, Faculty of Medicina, Universidad de Antioquia, Medellín, Colombia ${ }^{2}$ Molecular Systematics Research Group, Biosciences School - Sciences Faculty, Universidad Nacional de Colombia, Medellín, Colombia
}

Since the first reports of WNV isolation from Africa, Europe, India, Russia, Israel, France, and its 1999 introduction into North America, WNV has extended its geographic distribution throughout the United States [3]. Subsequently, in the following years this arbovirus was detected in Canada, Mexico, Guatemala, Caribbean islands, and South America [4-6]. Serologic evidence for the natural circulation of WNV in Colombia has been observed in equids sampled from the department of Córdoba [7, 8] and other regions from the Caribbean [9-11]. Despite WNV being isolated for the first time from captive flamingoes in Santa Fé Zoo (Medellín, Colombia) [12], it is not clear why WNV has not been isolated from or been the cause of detectable disease in horses or humans in Colombia. Possible explanations include: circulation of WNV in remote enzootic cycles
() Biomed Central

(c) 2015 López et al.; licensee BioMed Central. This is an Open Access article distributed under the terms of the Creative Commons Attribution License (http://creativecommons.org/licenses/by/4.0), which permits unrestricted use, distribution, and reproduction in any medium, provided the original work is properly credited. The Creative Commons Public Domain Dedication waiver (http://creativecommons.org/publicdomain/zero/1.0/) applies to the data made available in this article unless otherwise stated. 


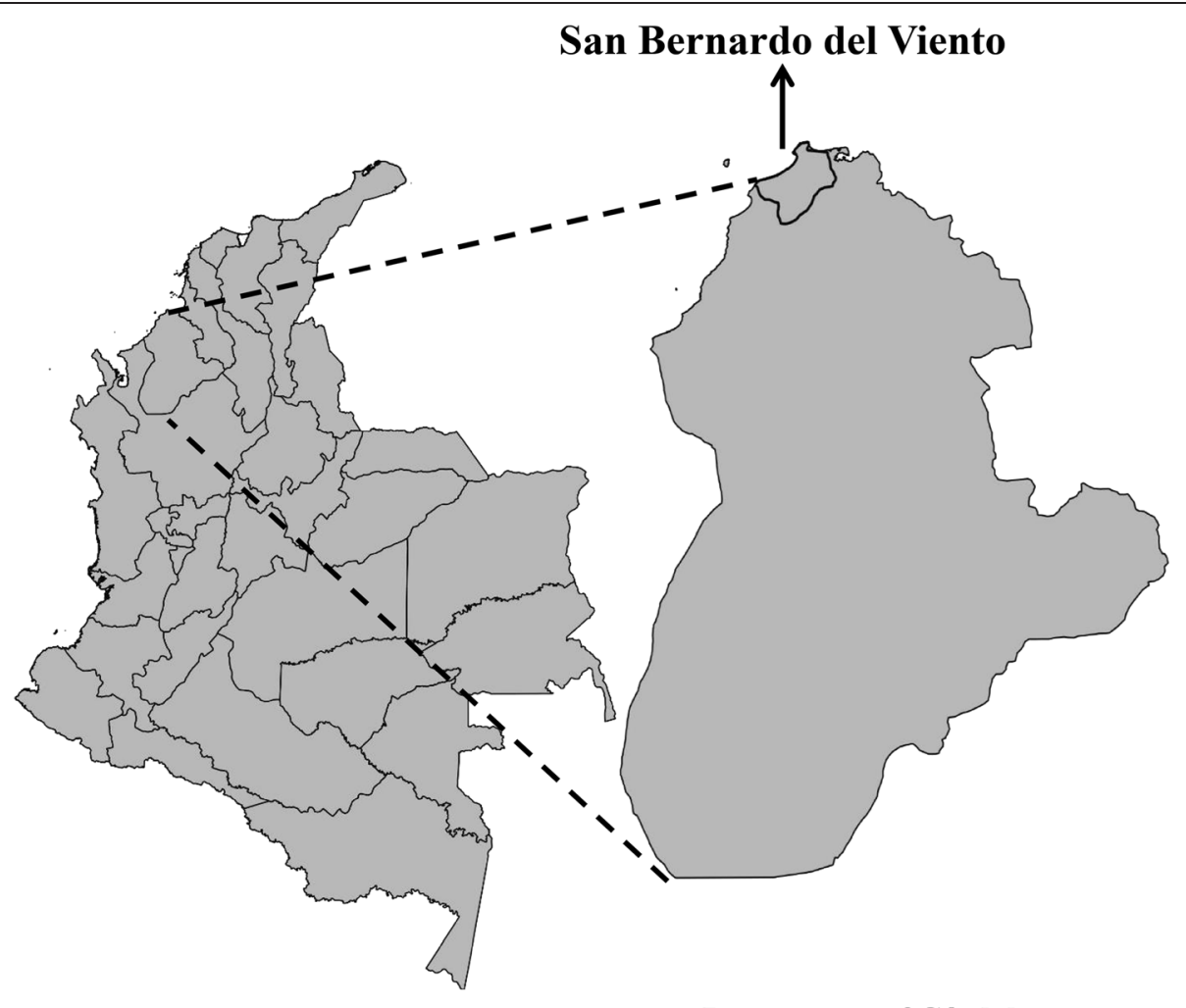

Colombia

Department of Córdoba

Fig. 1 Map of the study area showing San Bernardo del Viento (Córdoba, Colombia)

away from human settlements, limited vector competence of mosquito species, ornitophilic blood-feeding preferences, cross-protective immunity in humans from other flaviviruses (dengue, Saint Louis encephalitis viruses), or the circulation of WNV-strains with low or attenuated virulence [10-12].

WNV occurs in four major lineages, but lineage 1 is epidemiologically relevant. Lineage 1 is subdivided into three clades (1a, 1b, 1c); clade 1a contains isolates from Africa, Europe, the Middle East, Russia and Americas $[1,3]$. WNV-American strains have close relationships with three Old World isolates: IS98-ST1 (Israel - 1998), PaH001 (Tunez-1997) and goose-03 (Hungary-2003), and extensive studies have allowed detailed investigations of
WNV microevolution in different areas over time and also the emergence of new genotypes [3]. In this sense, phylogenetic analysis has enabled the understanding of epidemiological patterns of emergence, dispersal routes, adaptation to new hosts/mosquitoes species, and spatiotemporal patterns of evolution [1, 3, 5, 12]. Evolutionary studies are necessary to identify "drivers" of emergence, molecular evolution of virulence and associations to ecological factors that allow the establishment of this arbovirus pathogen in human populations.

Between 2011 and 2013, a surveillance study was performed at one locality that is characteristic of a large migratory bird population in northern Colombia. We detected WNV in pools of mosquitoes and amplified two

Table 1 Primers and RT-PCR (generic/nested) conditions for arboviral detection in target groups

\begin{tabular}{llll}
\hline Arboviruses group & Primers & Conditions for RT-PCR & Reference \\
\hline Flavivirus & Flavi1+ GAYYTIGGITGYGGIIGIGGIRGITGG & $1 \mathrm{cycle}-45 \mathrm{~min} / 38^{\circ} \mathrm{C}$ & $413]$ \\
& Flavi1- TCCCAICCIGCIRTRTCRTCIGC & $10 \mathrm{cycles}: 30 \mathrm{sec} / 94^{\circ} \mathrm{C}, 1 \mathrm{~min} / 47^{\circ} \mathrm{C}, 75 \mathrm{sec} / 68^{\circ} \mathrm{C}$ \\
& Flavi2+ YGYRTIYAYAWCAYSATGGG $-5 \mathrm{~min} / 68^{\circ} \mathrm{C}$ \\
& Flavi2- CCARTGITCYKYRTIIAIRAAICC & $1 \mathrm{cycle}-2 \mathrm{~min} / 94^{\circ} \mathrm{C}$ \\
& $40 \mathrm{cycles}: 30 \mathrm{sec} / 94^{\circ} \mathrm{C}, 1 \mathrm{~min} / 47^{\circ} \mathrm{C}, 15 \mathrm{sec} / 72^{\circ} \mathrm{C}$ \\
\hline
\end{tabular}


Table 2 Sequences downloaded of Genbank and background information of WNV strain/isolates used in this study

\begin{tabular}{|c|c|c|c|c|}
\hline Accession number & Strain & Location & Host-species & Year \\
\hline GQ379160 & ArEq001 & Argentina & Horse & 2006 \\
\hline GQ379161 & ArEq003 & Argentina & Horse & 2006 \\
\hline DQ118127 & goose-Hungary/03 & Hungary & goose & 2003 \\
\hline AF481864 & IS-98 ST1 & Israel & sick stork & 1998 \\
\hline DQ080065 & TVP9221 & Mexico:Baja Calfornia Norte & Grackel & 2003 \\
\hline DQ080064 & TVP9222 & Mexico:Baja Calfornia Norte & Coot & 2003 \\
\hline DQ080063 & TVP9223 & Mexico:Baja Calfornia Norte & Pigeon & 2003 \\
\hline DQ080066 & TVP9220 & Mexico:Baja Calfornia Norte & Cormorant & 2003 \\
\hline DQ080068 & TVP9218 & Mexico:Baja Calfornia Norte & Blue Heron & 2003 \\
\hline DQ080067 & TVP9219 & Mexico:Baja Calfornia Norte & Green Heron & 2003 \\
\hline DQ080070 & TVP9115 & Mexico:Sonora & Grackel & 2003 \\
\hline DQ080069 & TVP9117 & Mexico:Tamaulipas & Horse & 2003 \\
\hline DQ164201 & AZ 2004 (Arizona 2004) & USA: Arizona & Human- plasma & 2004 \\
\hline DQ080057 & CA-03 Arcadia-S0331532 (I) & USA: California, Los Angeles & Crow & 2003 \\
\hline DQ080058 & CA-03 Arcadia-S0334814 (J) & USA: California, Los Angeles & Crow & 2003 \\
\hline DQ080072 & FL232 & USA: Florida, Palm Beach Co. & Catbird & 2001 \\
\hline DQ080071 & FL234 & USA: Florida, Sumter Co. & Horse & 2002 \\
\hline GU827998 & Bird114 & USA: Harris County, Texas & blue jay & 2002 \\
\hline GU828002 & v4095 & USA: Harris County, Texas & Culex quinquefasciatus & 2003 \\
\hline GU828000 & Bird1175 & USA: Harris County, Texas & Blue jay & 2003 \\
\hline GU828003 & Bird1881 & USA: Jefferson County, Texas & Mourning dove & 2003 \\
\hline AF404753 & MD 2000-crow265 & USA: Maryland & Crow & 2000 \\
\hline AY795965 & ARC10-02 & USA: Michigan & Human- plasma & 2002 \\
\hline GU828004 & Bird1519 & USA: Montgomery County, Texas & Bluejay & 2003 \\
\hline DQ211652, AY842931 & NY99 385-99 & USA: New York & Snowy Owl & 1999 \\
\hline AF196835 & NY99-flamingo382-99 & USA: New York & Flamingo & 1999 \\
\hline AF202541 & HNY1999 & USA: New York & Human & 1999 \\
\hline AF260967 & NY99-eqhs & USA: New York & Horse & 1999 \\
\hline DQ164189 & NY 2003 Albany & USA: NY, Albany & American crow & 2003 \\
\hline DQ666452 & BSL2-05 & USA: South Dakota & Human- plasma & 2005 \\
\hline DQ164198 & TX 20021 (80025) & USA: Texas & Human- plasma & 2002 \\
\hline DQ164205 & TX 20022 (80022) & USA: Texas & Human- plasma & 2002 \\
\hline AY712945 & Bird 1153 (TWN274) & USA: Texas & Mourning dove & 2003 \\
\hline AY712946 & Bird 1171 (TWN269) & USA: Texas & Blue jay & 2003 \\
\hline AY712948 & V4369 (TWN382) & USA: Texas & Culex quinquefasciatus & 2003 \\
\hline DQ080053 & AZ-03 03-1799 & USA:Arizona, Apache Co. & Culex tarsalis & 2003 \\
\hline DQ080051 & AZ-03-1623 (A) & USA:Arizona, Cochise Co. & Culex tarsalis & 2003 \\
\hline DQ080052 & AZ-03-1681 (B) & USA:Arizona, Maricopoa Co. & Culex tarsalis & 2003 \\
\hline DQ080055 & CA-03 IMPR 102 (F) & USA:California, Imperial Valley & Culex tarsalis & 2003 \\
\hline DQ080056 & CA-03 IMPR-1075 (G) & USA:California, Imperial Valley & Culex tarsalis & 2003 \\
\hline DQ080054 & CA-03 GRLA-1260 & USA:California, Los Angeles & Culex quinquefasciatus & 2003 \\
\hline FJ527738 & LSU-AR01 & USA:Louisiana & Blue jay & 2001 \\
\hline DQ080062 & LA02-2829 (TWN165) & USA:Louisiana & Mosquito & 2002 \\
\hline DQ080061 & Bird2409 (TWN 496) & USA:Louisiana & Cardinal & 2004 \\
\hline
\end{tabular}


Table 2 Sequences downloaded of Genbank and background information of WNV strain/isolates used in this study (Continued)

\begin{tabular}{llll}
\hline HQ671697 & BID V4197-2001 & USA: Connecticut & Aedes vexans \\
KJ501528 & BID V6697-2002 & USA & Blue jay \\
AY646354 & USA & USA: New York & Human-plasma \\
DQ164199 & TX-2003 & USA: Texas & Human \\
AY660002 & Mex03 (TM171-03) & Mexico: Tabasco & Raven \\
JN716371 & COL524-08 & Colombia: Antioquia, Medellín & Flamingo \\
JN716372 & COL9835-08 & Colombia: Antioquia, Medellín & Flamingo \\
\hline
\end{tabular}

viral regions that were used to establish the phylogenetic relationships with strains isolated in the U.S., Mexico and Argentina, with the goal of defining the evolutionary relationships with genotypes previously isolated from outbreaks in the geographic areas mentioned above.

\section{Material and methods \\ Samples}

During virological surveillance for detection of emerging and re-emerging arboviruses between 2011-2013 in San Bernardo del Viento (Córdoba, Colombia) (9 $21^{\prime} 30.97^{\prime \prime} \mathrm{N}$, $75^{\circ} 58^{\prime} 37.28^{\prime \prime}$ W) (Fig. 1), mosquitoes were collected using CDC-light/EVS traps that were baited with dry ice $\left(\mathrm{CO}_{2}\right)$. All the insects sampled were separated into pools through morphological identification and triturated using minimum essential medium (MEM) supplemented with $10 \%$ fetal bovine serum, $1 \%$ penicillin, then clarified by centrifugation at 13,000 rpm for $30 \mathrm{~min}$. Supernatant was used for RNA extraction and generic nested reverse transcriptase polymerase chain reaction (RT-PCR) for detection of flaviviruses (Table 1) [13]. Two mosquito pools, each containing 40 and 50 specimens (whose mosquitoes had a high percentage $-99.57 \%$ of similarity in their DNA Barcode sequences with Culex (Melanoconion) erraticus) were positive for a member of the Flavivirus genus. Sequencing of PCR-products, BLASTN and NeighborJoining phylogenetic analysis allowed identification of these sequences as West Nile virus.

\section{Molecular protocols}

Total RNA was extracted from the PCR-positive homogenates with the RNeasy kit (Qiagen, Valencia) and used for RT-PCR using the One-Step RT-PCR Kit (Qiagen, Valencia, CA) as described previously $[14,15]$. Two viral genes were amplified: NS5 (primers: FU1PMF-TACAACATGATGGG VAARAGWGARAA/cFD3PMR-ARCATGTCTTCYGTB GTCATCCA) and Envelope (primers: WN1101-GATG AATATGGAGGCGGTCA/WN1816A-CCGACGTCAAC TTGACAGTG and WN1751-TGCATCAAGCTTTGG CTGGA/WN2504A TCTTGCCGGCTGATGTCTAT).

\section{Sequence analysis}

A total of 46 genome sequences of envelope/NS5 from WNV isolates, representative of American clade 1a-Cluster 4 geographic locations [16], were downloaded from GenBank (Table 2). Nucleotide sequences were aligned using the MAFFTv7.0 (http://mafft.cbrc.jp/ alignment/server/) and then transferred in FASTA format to BioEdit (http://www.mbio.ncsu.edu/BioEdit/bioedit.html) for manual editing, keeping gaps consistent within the reading frame. The sequences of NS5 and envelope of the WNV-strains were aligned and evaluated in jModelTest v2.1.4 [17] using the Akaike criterion informative for identify appropriate substitution model nucleotide. One test was also performed for concatenated sequences. The XML file for Bayesian analysis was created in BEAUti v1.5.4 (http:// www.molecularevolution.org/software/phylogenetics/ beauti), describing model of sequences, invariants, gamma distribution, size of the chain run (20 million of generations), coalescent constant population and for accommodate the variation in substitution rate among branches, a random local clock model was chosen for this analysis [18].

Bayesian phylogenetic analysis was performed using the BEAST software package v2.1.3 [19], and estimation of the maximum clade credibility (MCC) phylogenetic tree was achieved using TreeAnnotator-v2.0.2. BEAST output was viewed with TRACERv-1.5 and evolutionary trees were generated in the FigTree-v1.3.1.

DNAsp-v5.0 [20] was used to establish polymorphic sites between NS5/envelope sequences characterized in our study and reference sequences of representative WNV strains.

\section{Results and discussion}

The two pools infected with WNV, corresponding probably to the mosquito species Culex (Melanoconion) erraticus (codes: CDCCA4-12 - CDCCZ2-21), were collected in September, 2012 from coastal mangroves in a migratory bird zone located in San Bernardo del Viento (Córdoba Department). Both isolates were RT-PCR amplified, including one sequence of 1504 nt in length from the 


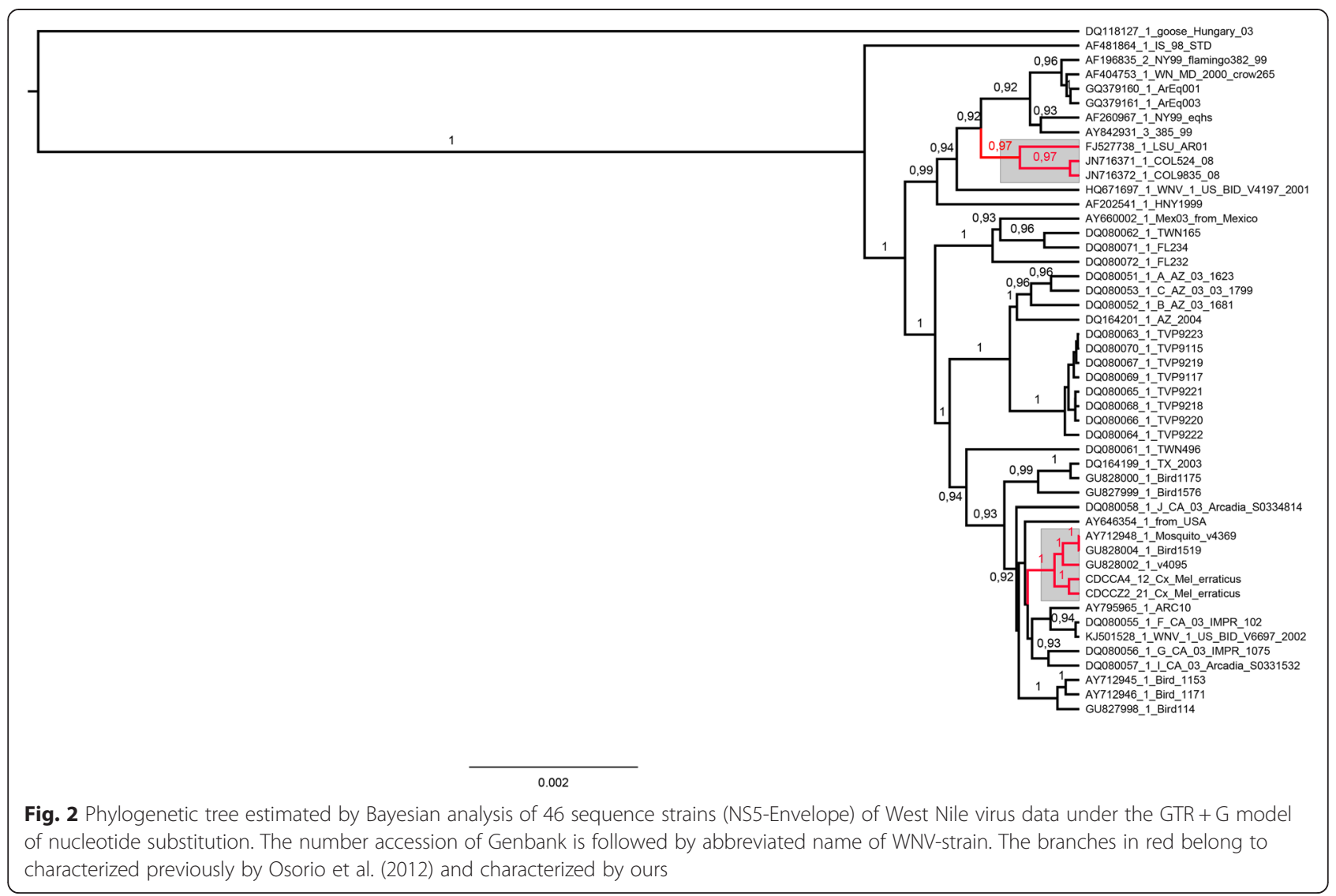

envelope gene (Genbank accession number: KM212943 KM212944) and another 1186 nt long from the NS5 gene (Genbank accession number: KM212941 - KM212942). jModelTest-v2.1.4 estimated the same model of substitution nucleotide, General-Time-Reversible (GTR) + gamma distribution $(-\operatorname{lnL}=4792.34$, AICc $=9798.9686)$ for both viral regions. A concatenated file with two NS5/envelope sequences (2690 nt) estimated the same model and was used for phylogenetic inference.

The phylogenetic tree inferred with Bayesian methods indicated that our two WNV-samples were closely related to strains Mosquito-v4369, Bird1519 and v4095, all belonging to southeastern coastal Texas genotype (Fig. 2). Our sequences differed from that of this WNV-genotype in three positions in the envelope gene: only two positions are unique (shaded positions: 547,641 ) and position 555 shared the same nucleotide with strains HNY1999, COL524 and COL9835. These substitutions were all synonymous. No unique mutations were found in NS5, but our sequences shared similar differences to the WNVTexas genotype and other WNV genotypes (Table 3). The southeastern coastal Texas genotype includes several isolates collected in 2002 from Texas, and is considered to have an attenuated phenotype with a small plaques (sp) size, temperature sensitivity (ts), reduced replication in cell culture and reduced neuroinvasiveness that is dose-
Table 3 Polymorphic sites between envelope and NS5 sequences belonging to southeastern coastal Texas genotype and our samples from Northern of Colombia (Córdoba, San Bernardo del Viento)

\begin{tabular}{lll}
\hline Sequences & \multicolumn{2}{l}{ Polymorphic sites } \\
\cline { 2 - 3 } & Envelope & NS5 \\
& 1 & 11222222 \\
& 22455695 & 57012222 \\
& 834745480 & 91811266 \\
& 440675140 & 93524727 \\
\hline AF202541.1 HNY1999 & TGCTTGAGC & TCCTTCCG \\
JN716371.1 COL524 & CAT...T. & ...C.T. \\
JN716372.1 COL9835 & CAT...... & ...C..T. \\
AY712948.1 Mosquito-v4369 & CATC.A..T & CTT..TT. \\
GU828004.1 Bird1519 & CATC.A..T & CTT..TTA \\
GU828002.1 v4095 & CATC.A..T & C.T.CTT. \\
CDCCA4-12 Cx.erraticus & CATCC.G.T & C.T..TT. \\
CDCCZ2-21 Cx.erraticus & CATCC.G.T & C.T..TT. \\
\hline
\end{tabular}

Number represented polymorphic positions inside alignment of envelope and NS5 sequences and dots indicate sequence homology. Nucleotides in shadow evidenced unique substitutions that distinguish WNV-detected in mosquito pools from other strains 
dependent [21]. The southeastern coastal Texas genotype has not been detected since 2002, suggesting its possible extinction [3]. In Colombia, previous work characterizing WNV-strains isolated from flamingoes (COL524/COL9835) showed a close genetic relationship with WNV strains isolated in Louisiana in 2001 and the NY99 strain (Fig. 2), but in vitro phenotypic characterization showed differences with the attenuated Texasgenotype. In fact, COL524/COL9835 has high virulence in chicken eggs and newborn/4-week-old Balb/c mice [12].

Our results demonstrate genetic diversity of WNV strains circulating in Colombia. The presence of the attenuated coastal Texas genotype could explain, in part, the lack of human and equine cases detected. Previous work has shown WNV-seropositivity in horses from the Caribbean region with no disease reported [7-11]. Different WNV genotypes may converge along migratory bird flyways, which pass from the U.S. to Mexico, Colombia and Venezuela, Caribbean Islands, and other parts of South America south to Argentina. The high diversity of migratory birds in certain areas of Caribbean Colombia [3, 4, 12, 22] may be important for WNV maintenance.

Finally, our results indicate a close evolutionary relationship with the attenuated coastal Texas genotype requires further studies in cell culture and animal models to confirm the attenuated phenotype. Additional surveillance focused on avian and mosquito fauna is also needed to obtain more isolates of WNV in conserved Colombian ecosystems to further examine the genetic diversity of WNV and possible strain dissemination to another geographic areas.

\section{Competing interests}

The authors declare that they have no competing interests.

\section{Authors' contributions}

$\mathrm{RHL}$ performed the molecular experiments, phylogenetic analysis and wrote the first draft of the paper. JCGG conceived the study, SIU help with design and develop study. SIU and JCGG critically reviewed this manuscript. All authors read and approved the final manuscript.

\footnotetext{
Acknowledgements

$\mathrm{RHL}$ was recipient of a doctoral fellowship from "Programa de Doctorados Nacionales - Colciencias" (Convocatoria 528). The authors acknowledge to "Departamento Administrativo de Ciencia, Tecnología e Innovación - Colciencias" by supporting research with grant 111549326198 . Finally, JCGG was recipient of a Full-Time Professor Program ("Dedicación Exclusiva") 2012-3 of the Medicine Faculty at Universidad de Antioquia.

To the entomologist Juan David Suaza who helped in all field work and entomological processing of the samples. Also to the direction and personnel of Laboratory of Biology and Insect Systematics, Sciences Faculty, Universidad Nacional de Colombia, sede Medellin, where all the molecular work was done. To Drs. Scott Weaver and Albert Auguste from National Galveston Laboratory Medical Branch of Texas University (UTMB).
}

Received: 29 January 2015 Accepted: 13 May 2015

Published online: 20 May 2015

\section{References}

1. Kramer L, Styer L, Ebel G. A Global Perspective on the epidemiology of West Nile virus. Annu Rev Entomol. 2008;53:61-81.

2. Samuel M, Diamond M. Pathogenesis of West Nile Virus Infection: a Balance between Virulence, Innate and Adaptive Immunity, and Viral Evasion. J virol. 2006;80:9349-60.

3. Mann B, McMullen A, Swetnam D, Barret A. Molecular Epidemiology and Evolution of West Nile Virus in North America. Int J Environ Res Public Health. 2013;10:5111-29.

4. Komar N, Clarck G. West Nile virus activity in Latin America and Caribbean. Rev Panam Salud Publica. 2006;19:112-7.

5. Morales MA, Barrandeguy M, Fabbri C, Garcia JB, Vissani A, Trono K, et al. West Nile virus isolation from equines in Argentina, 2006. Emerg Infect Dis. 2006;10:1559-61.

6. Ometto T, Durigon EL, de Araujo J, Aprelon R, de Aguiar DM, Cavalcante GT, et al. West Nile virus surveillance, Brazil, 2008-2010. Trans R Soc Trop Med Hyg. 2013;107:723-30.

7. Mattar S, Edwards E, Laguado J, González M, Alvarez J, Komar N. West Nile virus infection in Colombian horses. Emerg Infect Dis. 2005;11:1497-8.

8. Jaramillo M, Peña J, Berrocal L, Komar N, González M, Ponce C, et al. Vigilancia centinela para el Virus del Oeste del Nilo en Culícidos y Aves Domésticas en el Departamento de Córdoba. Rev MVZ Cordoba. 2005; 10:633-8.

9. Mattar S, Parra M, Torres J. Limitaciones para el serodiagnóstico del virus del Nilo del oeste en zonas endémicas con co-circulación de Flavivirus en el Caribe colombiano. Colombia Médica. 2005;36:179-85.

10. Góes-Rivillas Y, Taborda N, Díaz F, Góngora A, Rodas JD, Ruiz-Sáenz J, et al. Antibodies to West Nile virus in equines of Antioquia and Meta, Colombia, 2005-2008. Rev Colomb Cienc Pecu. 2010;23:462-70.

11. Mattar S, Komar N, Young G, Alvarez J, Gonzalez M. Seroconversion for West Nile and St. Louis encephalitis viruses among sentinel horses in Colombia. Mem Inst Oswaldo Cruz. 2011;106:976-9.

12. Osorio J, Ciuoderis K, Lopera J, Piedrahita L, Murphy D, Levasseur J, et al. Characterization of West Nile Viruses isolated from captive American flamingoes (Phoenicopterous ruber) in Medellin, Colombia. Am J Trop Med Hyg. 2012;87:565-72.

13. Sánchez-Seco M, Rosario D, Domingo C, Hernández L, Valdés K, Gúzman M, et al. Generic RT-nested-PCR for detection of flaviviruses using degenerated primers and internal control followed by sequencing for specific identification. J Virol Methods. 2005;1:101-9.

14. Kuno G, Chang GJ, Tsuchiya KR, Karabatsos N, Cropp CB. Phylogeny of the genus Flavivirus. J Virol. 1998;72:73-83.

15. Beasley DWC, Davis CT, Guzman H, Vanlandingham DL, Travassos da Rosa APA, Parsons RE. Limited evolution of West Nile virus has occurred during its southwesterly spread in the United States. Virology. 2003;309:190-5.

16. May F, Davis T, Tesh R, Barrett A. Phylogeography of West Nile Virus: from the Cradle of Evolution in Africa to Eurasia, Australia, and the Americas. J Virol. 2011:85:2964-74.

17. Darriba D, Taboada GL, Doallo R, Posada D. jModelTest 2: more models, new heuristics and parallel computing. Nat Methods. 2012;9:772.

18. Drummond A, Suchard M. Bayesian random local clocks, or one rate to rule them all. BMC Biol. 2010;8:114.

19. Bouckaert R, Heled J, Kühnert D, Vaughan TG, Wu C-H, Xie D, et al. BEAST2: A software platform for Bayesian evolutionary analysis. PLOS Comput Biol. 2014;10, e1003537.

20. Librado P, Rozas J. DnaSP v5: A software for comprehensive analysis of DNA polymorphism data. Bioinformatics. 2009;25:1451-2.

21. Davis T, Beasley D, Guzman H, Siirin M, Parsons R, Tesh R, et al. Emergence of attenuated West Nile virus variants in Texas, 2003. Virology. 2004;320:342-50.

22. Berrocal L, Peña J, González M, Mattar S. West Nile virus; ecology and epidemiology of an emerging pathogen in Colombia. Rev salud pública. 2006;8:218-28 